\title{
The global climatology of the intensity of the ionospheric sporadic $E$ layer
}

\author{
Bingkun Yu ${ }^{1,2,3}$, Xianghui Xue ${ }^{1,2,4}$, Xin'an Yue ${ }^{5}$, Chengyun Yang ${ }^{1,2}$, Chao Yu ${ }^{1,2}$, Xiankang Dou ${ }^{1,2}$, Baiqi Ning ${ }^{5}$, and \\ Lianhuan $\mathrm{Hu}^{5}$ \\ ${ }^{1}$ CAS Key Laboratory of Geospace Environment, Department of Geophysics and Planetary Sciences, \\ University of Science and Technology of China, Hefei, China \\ ${ }^{2}$ Mengcheng National Geophysical Observatory, School of Earth and Space Sciences, \\ University of Science and Technology of China, Hefei, China \\ ${ }^{3}$ Department of Meteorology, University of Reading, Reading, Berkshire, UK \\ ${ }^{4}$ Synergetic Innovation Center of Quantum Information and Quantum Physics, \\ University of Science and Technology of China, Hefei, China \\ ${ }^{5}$ Key Laboratory of Earth and Planetary Physics, Institute of Geology and Geophysics, \\ Chinese Academy of Sciences, Beijing, China
}

Correspondence: Xianghui Xue (xuexh@ustc.edu.cn)

Received: 31 July 2018 - Discussion started: 2 October 2018

Revised: 10 February 2019 - Accepted: 22 March 2019 - Published: 2 April 2019

\begin{abstract}
On the basis of S4max data retrieved from COSMIC GPS radio occultation measurements, the long-term climatology of the intensity of $E_{\mathrm{s}}$ layers is investigated for the period from December 2006 to January 2014. Global maps of $E_{\mathrm{s}}$ intensity show the high-spatial-resolution geographical distribution and strong seasonal dependence of $E_{\mathrm{s}}$ layers. The maximum intensity of $E_{\mathrm{s}}$ occurs over the mid-latitudes, and its value in summer is 2-3 times larger than that in winter. A relatively strong $E_{\mathrm{S}}$ layer is observed at the North Pole and South Pole, with a distinct boundary dividing the midlatitudes and high latitudes along the $60-80^{\circ}$ geomagnetic latitude band. The simulation results show that the convergence of vertical ion velocity could partially explain the seasonal dependence of $E_{\mathrm{s}}$ intensity. Furthermore, some disagreements between the distributions of the calculated divergence of vertical ion velocity and the observed $E_{\mathrm{s}}$ intensity indicate that other processes, such as the vertical motions of gravity waves, magnetic-field effects, meteoric mass influx into Earth's atmosphere, and the chemical processes of metallic ions, should also be considered as they may also play an important role in the spatial and seasonal variations in $E_{\mathrm{s}}$ layers.
\end{abstract}

\section{Introduction}

Ionospheric sporadic $E\left(E_{\mathrm{S}}\right)$ layers are thin-layered structures with intense, high electron densities at $90-130 \mathrm{~km}$ altitudes. Rocket-borne mass-spectrometric measurements have shown that the $E_{\mathrm{s}}$ layer mostly result from the ionisation of metal atoms, such as $\mathrm{Fe}^{+}, \mathrm{Mg}^{+}$, and $\mathrm{Na}^{+}$(Kopp, 1997; Grebowsky and Aikin, 2002). The $E_{\mathrm{s}}$ layer mainly resides over mid-latitudes and is relatively absent at the geomagnetic equator and high latitudes (Whitehead, 1989). It is widely accepted that the mechanism responsible for $E_{\mathrm{S}}$ layer formation at mid-latitudes is wind shear, in which the zonal and meridional winds provide vertical wind shear convergence nodes. As a result, long-lived metallic ions are forced to converge towards the wind shear null to form a thin layer of intense metallic ionisation (Whitehead, 1961, 1970, 1989; Macleod, 1966; Nygren et al., 1984; Haldoupis, 2012). In the equatorial region, the physical process of $E_{\mathrm{s}}$ irregularities is attributed to the gradient-drift instabilities associated with the equatorial electrojet (Tsunoda, 2008). At high magnetic latitudes, the vertical motion of gravity waves is very efficient in concentrating the ionisation of $E_{\mathrm{s}}$ because the magnetic-field lines are nearly vertical in the polar gap (Bautista et al., 1998; MacDougall et al., 2000a, b; MacDougall and Jayachandran, $2005)$. The $E_{\mathrm{s}}$ layer generally has a vertical scale of $1 \mathrm{~km}$ 
or less, but its horizontal scale can extend up to several hundreds of kilometres. Consequently, intense $E_{\mathrm{s}}$ plasma irregularities and their sharp vertical electron density gradients seriously affect radio communications and navigation systems (Pavelyev et al., 2007). Furthermore, these effects on global positioning system (GPS) radio occultation (RO) signals detected by low-Earth-orbit (LEO) satellites can be exploited for lower-level atmospheric and ionospheric global investigations (Rocken et al., 2000; Hocke and Tsuda, 2001; Schreiner et al., 2007; Yue et al., 2010, 2011).

Observations of $E_{\mathrm{S}}$ layers have been widely investigated from ground-based radars (e.g. Farley, 1985; Whitehead, 1989; Kelly, 1989; Chu and Wang, 1997; Mathews, 1998). In addition to ground-based radars, the scintillations of GPSRO were employed to extensively investigate $E_{\mathrm{s}}$ layers over the past few decades (Wu et al., 2005; Arras et al., 2008; Zeng and Sokolovskiy, 2010; Chu et al., 2011). A global map of $E_{\mathrm{s}}$ layers was first presented based on a meridional chain of ionosonde stations (Leighton et al., 1962). In recent years, based on GPS-RO measurements, knowledge of the global $E_{\mathrm{S}}$ layer occurrence rate (hereafter called $E_{\mathrm{S}} \mathrm{OR}$ ) has been advanced remarkably. Wu et al. (2005) used phase and signal-to-noise ratio (SNR) variations from $\sim 6000$ GPSChallenging Minisatellite Payload (CHAMP) occultations to study the global climatology of $E_{\mathrm{s}} \mathrm{OR}$. Arras et al. (2008) investigated the global $E_{\mathrm{S}} \mathrm{OR}$ distribution, with a resolution of $5^{\circ} \times 5^{\circ}$, based on CHAMP, GRACE (Gravity Recovery and Climate Experiment), and COSMIC (Constellation Observing System for Meteorology, Ionosphere, and Climate) occultation data. These previous studies of global $E_{\mathrm{s}} \mathrm{OR}$ maps show a strong seasonal variation, with a summer maximum in the mid-latitudes. Chu et al. (2014) employed COSMIC measurements to study the global morphology of $E_{\mathrm{S}} \mathrm{OR}$ and the results of the theoretical simulations suggested that the $E_{\mathrm{S}} \mathrm{OR}$ seasonal variation is likely attributed to the convergence of the metallic ion flux caused by vertical wind shear. Shinagawa et al. (2017) calculated the global distribution of the vertical ion convergence and showed that local and seasonal variations in wind shear distribution could partially account for the geographical and seasonal variation in $E_{\mathrm{s}} \mathrm{OR}$.

Many papers have reported the geographical distribution and seasonal variation in global $E_{\mathrm{S}}$ layers retrieved from GPS-RO signals, and nearly all of these works focused on the $E_{\mathrm{s}} \mathrm{OR}$. The global climatology of the intensity of $E_{\mathrm{S}}$ layers has not been fully studied. The purpose of this paper is to study the global intensity of $E_{\mathrm{S}}$ layers and compare the results of $E_{\mathrm{S}}$ intensity with previous studies on the $E_{\mathrm{s}} \mathrm{OR}$. The occurrence of $E_{\mathrm{S}}$ layers can cause both SNR fluctuations and relative slant total electron content (TEC) peaks (Yue et al., 2015). Sometimes, the SNR has specific U-shaped structures in the amplitude of GPS-RO signals, as reported by Zeng and Sokolovskiy (2010) and Yue et al. (2015). The obvious increase in slant TEC occurring at approximately $92 \mathrm{~km}$ implies ionisation enhancement in $E_{\mathrm{s}}$. In this study, the scintillation index (S4 index) data, measured from SNR fluctu- ations in the L1 channel of the COSMIC GPS-RO profiles at altitudes between 90 and $130 \mathrm{~km}$ for the period from December 2006 to January 2014, are employed to study the global climatology of the ionisation of $E_{\mathrm{S}}$ layers. Section 2 describes the used data sets and procedures adopted to derive the S4 index. In Sect. 3, the global long-term behaviours of $E_{\mathrm{S}}$ layers with a high spatial resolution are presented and compared with the previous $E_{\mathrm{s}} \mathrm{OR}$ results, including the latitude-day, latitude-longitude, and altitude-latitude distributions; seasonal variations; and geomagnetic dependence of $E_{\mathrm{S}}$ layers. In Sect. 4, on the basis of the wind shear combined with several global-scale models, namely the Whole Atmosphere Community Climate Model (WACCM) (Marsh et al., 2013), the Naval Research Laboratory (NRL) Mass Spectrometer and Incoherent Scatter (MSIS)-00 atmospheric model (Picone et al., 2002), and the International Geomagnetic Reference Field (IGRF)-12 geomagnetic-field model (Thébault et al., 2015), we calculate the global distribution of the divergence of metallic ion velocity for comparison with the observations of $E_{\mathrm{s}}$ layers from COSMIC satellites. The effect of the magnetic declination angle on the divergence of the metallic ion velocity in the simulation of $E_{\mathrm{S}}$ is investigated for the first time. Section 5 presents the discussion and conclusions of this paper.

\section{Data and procedure of deriving the $\mathrm{S} 4$ index}

The COSMIC global data sets used in this study are the COSMIC-GPS amplitude S4 indices. The GPS radio signals are received by the precise orbit determination antennas of COSMIC for each GPS-RO when a GPS sets or rises behind Earth's atmosphere, as seen by the LEO satellite. Once the GPS signal is received at the LEO satellite, the onboard algorithm of the GPS receiver measures SNR intensity fluctuations from the raw $50 \mathrm{~Hz} \mathrm{L1}$ amplitude measurements, which are then recorded in the data stream at a $1 \mathrm{~Hz}$ rate at the ground receiver to minimise the data record size (Syndergaard et al., 2006). The raw scintillation measurements from the receiver are therefore the root mean square (rms) of the SNR intensity fluctuation in $1 \mathrm{~s}$ (i.e. $\left.\sigma_{I}\right)$, which can be expressed as $\sigma_{I}=\sqrt{\left\langle(I-\langle I\rangle)^{2}\right\rangle}$. $I$ represents the square of the L1 SNR, and the bracket \langle\rangle denotes the $1 \mathrm{~s}$ averaged value. The S4 indices are reconstructed by the COSMIC Data Analysis and Archive Center (CDAAC) ground processing after these $\sigma_{I}$ data are downloaded (Rocken et al., 2000). During the procedure of deriving the $\mathrm{S} 4$ indices, two additional steps are included in the ground processing. The first step is to assume that the SNR intensity fluctuations have Gaussian distributions to calculate an approximate value of $\langle I\rangle$ from $\sigma_{I}$ and $\langle\mathrm{SNR}\rangle$. The second is to apply a low-pass filter to the time series of $\langle I\rangle$ to obtain a new average of the intensity $\langle I\rangle_{\text {new }}$ at each second to replace the $\langle I\rangle$ in the calculation of the S4 indices. After these steps, a long-term detrended S4 index can be reconstructed by CDAAC ground processing. 
Further details on the procedure of deriving the S4 index, along with some individual example figures, can be found in the report of Ko and Yeh (2010).

In the present study, the COSMIC global data sets specifically denote the maximum value of S4 (S4max). The COSMIC global S4max data include the S4max value and geographic latitude, longitude, altitude and local time at which S4max was detected. The computed detrended S4max index is available from 28 December 2006 onwards on the CDAAC website (http://cdaac-www.cosmic.ucar.edu/cdaac, last access: 30 December 2017). The long-term global climatology of the $E_{\mathrm{s}}$ intensity is investigated based on the global S4max data from December 2006 to January 2014. Figure 1 shows the altitude distribution of the COSMIC S4max profiles. A considerable number of profiles are distributed at altitudes between 40 and $130 \mathrm{~km}$, with a peak number at approximately $100 \mathrm{~km}$. Information on $E_{\mathrm{s}}$ layers can be extracted from amplitude fluctuations in the SNR profiles (Wu et al., 2005). Please note that as a result of the integrated influence either in the SNR or the slant TEC along the LEO-GPS ray, the effect of $E_{\mathrm{s}}$ layers at high altitudes could map down to the lower tangent point altitudes, which may virtually induce multiple peaks in one RO event (Zeng and Sokolovskiy, 2010; Yue et al., 2015). In Fig. 1, the occurrence of sporadic $E$ can be seen down to $40 \mathrm{~km}$ as a result of an integral problem with using $\mathrm{RO}$ measurements. In fact, $E_{\mathrm{S}}$ layers could not be formed by the wind shear below $90 \mathrm{~km}$ because of the high ion-neutral collision frequencies. The $E_{\mathrm{s}}$ layer over lower altitudes (between 40 and $90 \mathrm{~km}$ ) should be some artefact resulting from the mapping effect integrated along the LEO-GPS ray. Therefore, the S4max values that appear in altitudes ranging between 90 and $130 \mathrm{~km}$ are used to study the $E_{\mathrm{S}}$ layers in the lower ionosphere region. Figure 2 shows the entire distribution of the daily average $E_{\mathrm{S}}$ intensity from 2006 to 2014 retrieved from COSMIC within $\pm 2.5^{\circ}$ latitude and longitude of one ionosonde station in Beijing $\left(40.3^{\circ} \mathrm{N}\right.$, $\left.116.2^{\circ} \mathrm{E}\right)$, which agrees with the ionosonde measurements $\left(f_{o} E_{\mathrm{S}}\right)$. The global morphology of the $E_{\mathrm{S}}$ intensity is presented, and its altitude and seasonal dependences are given at a high spatial resolution because of the large COSMIC RO data sets that have high vertical resolutions.

\section{Observations}

Figure 3 shows the long-term time series of the $E_{\mathrm{s}}$ values, with a resolution of $5^{\circ}$ latitude $\times 5$ days. As shown, the $E_{\mathrm{s}}$ layer is mainly a sporadic-layered phenomenon in the summer hemisphere, as is known from former $E_{\mathrm{S}} \mathrm{OR}$ studies (Leighton et al., 1962; Wu, 2006; Arras et al., 2008; Chu et al., 2014). In Fig. 3, it is clear that the intensity of $E_{\mathrm{s}}$ is enhanced in the northern (southern) summer hemisphere from May to September (from November to March), with a maximum in June (December) (i.e. 1 month ahead of the $E_{\mathrm{s}} \mathrm{OR}$ maximum, Chu et al., 2014). In addition, the seasonal
$E_{\mathrm{s}}$ layer also has inter-annual variability. Compared with the intense $E_{\mathrm{S}}$ activity in the summers of 2010 and 2011, the intensity of $E_{\mathrm{S}}$ is lower in the northern summers of 2012 and 2013 , respectively. This result may be caused by anomalies in the wind field in the upper atmosphere and a corresponding reduction in the vertical wind shear associated with $E_{\mathrm{s}}$ formation.

The map in Fig. 4 shows the global geographical distributions of the $E_{\mathrm{s}}$ average intensity, using a significantly improved spatial resolution of $1^{\circ} \times 1^{\circ}$. The red and green solid curves represent the northern and southern geomagnetic latitude contours of 60,70 , and $80^{\circ}$, respectively. The geomagnetic equator is also plotted with a yellow curve. The $E_{\mathrm{s}}$ layers are predominantly distributed with S4max values exceeding 0.7 at mid-latitudes. Because of the increased spatial resolution, the regional features and longitudinal variations become visible. The intensity of $E_{\mathrm{s}}$ is much weaker at the lower latitudes in both hemispheres, especially in the noticeable gap near the magnetic equator. When the magnetic field is horizontal at the geomagnetic equator, below the zonal wind shear action, ions move vertically due to the Lorentz force. However, they fail to converge into a layer because they are withheld by magnetised electrons. The plasma remains locally neutral. For a meridional wind shear process, ions move along the magnetic-field lines without being acted upon by Lorentz forces (Haldoupis, 2012). Therefore, a noticeable gap near the magnetic equator could be expected, which is explained by the vanishing vertical component of the geomagnetic-field lines, keeping the ionised particles from effectively vertically converging. This gap could also be found in the distribution of $E_{\mathrm{s}} \mathrm{OR}$, although it is not as evident in Arras et al. (2008).

Furthermore, the $E_{\mathrm{S}}$ longitudinal variations in the geomagnetic field are also clearly shown. The decrease in $E_{\mathrm{S}}$ intensity can be seen clearly in the South Atlantic Anomaly (SAA) zone and the North American region with geomagnetic latitude. The region of large $E_{\mathrm{s}}$ intensity exists in the North African and North Atlantic regions, Southeast Asian region, southern African and South Pacific regions. There is a difference between the $E_{\mathrm{S}}$ intensity and $E_{\mathrm{s}} \mathrm{OR}$ distributions at high latitudes: that is, the occurrence rates of $E_{\mathrm{S}}$ are generally low (Arras et al., 2008), but the intensity of $E_{\mathrm{s}}$ is relatively high. This pattern is more evident over the magnetic poles, which is likely the result of vertical motions of gravity waves in concentrating the ionisation of $E_{\mathrm{s}}$ layers (MacDougall et al., $2000 \mathrm{a}, \mathrm{b})$. The lower panels depict the northern and southern polar views of the distributions of $E_{\mathrm{s}}$ intensity, and these views make the features clearer.

The maps in Fig. 5 show the geographical distribution of $E_{\mathrm{S}}$ intensity for four different seasons in a $1^{\circ} \times 1^{\circ}$ grid. The distribution of $E_{\mathrm{s}}$ layers shows a significant seasonal dependence. The intensity of the $E_{\mathrm{S}}$ layers in the mid-latitudes of the summer hemisphere is 2-3 times larger than that in the winter hemisphere. During spring and autumn, the intensity of the $E_{\mathrm{S}}$ layers is moderate, covering the entire globe, and 


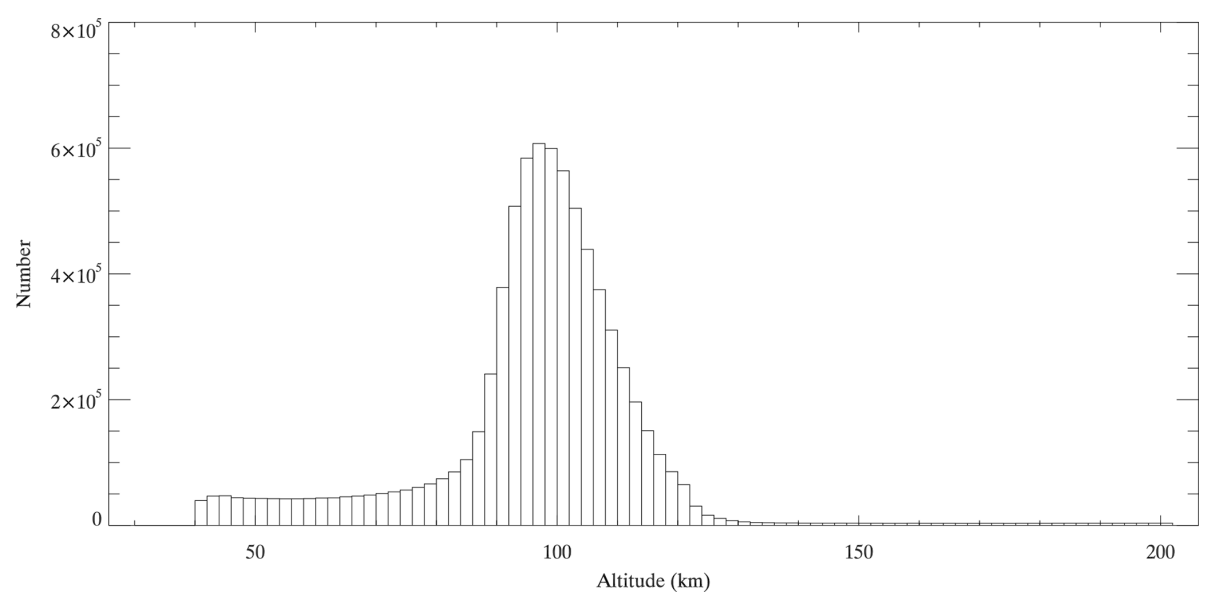

Figure 1. The altitude distribution of COSMIC S4max profiles from December 2006 to January 2014.

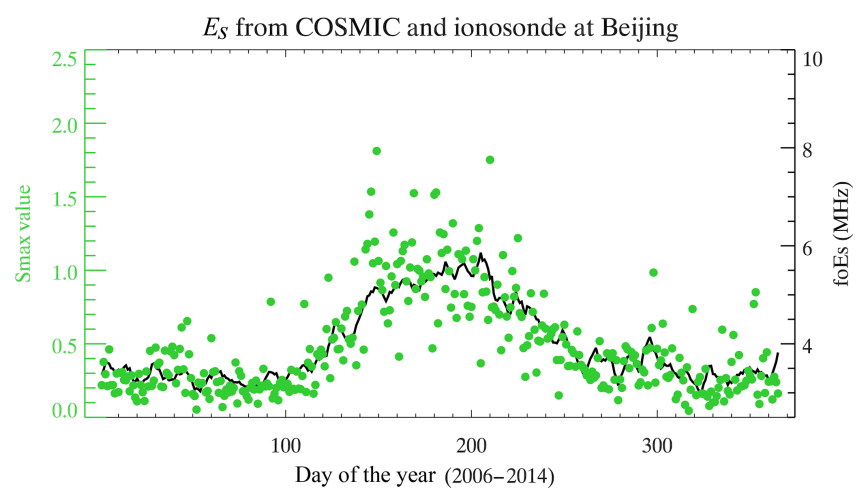

Figure 2. The entire distribution of the daily average $E_{\mathrm{s}}$ intensity retrieved from COSMIC within $\pm 2.5^{\circ}$ latitude and longitude of one ionosonde station and ionosonde data $\left(f_{o} E_{\mathrm{S}}\right)$ in Beijing from 2006 to 2014 .

a distinct boundary dividing the mid-latitudes and high latitudes is visible along the $60-80^{\circ}$ geomagnetic latitude band. From the polar views during each season, it can be seen that the $E_{\mathrm{s}}$ layers remain at a relatively high level at the North Pole and South Pole. This characteristic could be attributed to high energy radiation, particle precipitation, and polar gap gravity waves.

Figure 6 shows the altitude-latitude distribution of the $E_{\mathrm{s}}$ intensity with a resolution of $1 \mathrm{~km}$ altitude $\times 1^{\circ}$ latitude. The intensity of $E_{\mathrm{s}}$ is distributed at altitudes between 95 and $125 \mathrm{~km}$. The densest patches of $E_{\mathrm{s}}$ exist at altitudes exceeding $110 \mathrm{~km}$, which is different from the $E_{\mathrm{S}} \mathrm{OR}$ altitudelatitude distribution that dominates at $95-110 \mathrm{~km}$, with a peak at approximately $105 \mathrm{~km}$ in the mid-latitudes of $25-45^{\circ}$ (Arras et al., 2008). The $E_{\mathrm{s}}$ intensity has a broader latitudinal extent of $10-75^{\circ} \mathrm{S}$ in the Southern Hemisphere, compared with $10-60^{\circ} \mathrm{N}$ in the Northern Hemisphere.

Figure 7 presents the seasonal variation in the altitudelatitude distributions of the $E_{\mathrm{s}}$ intensity for the same tem- poral period and spatial resolution as those in Fig. 6. The $E_{\mathrm{s}}$ intensity for the summer and winter solstices clearly has a significantly broader latitudinal extent towards the highlatitude region. In addition, the overall intensities of the $E_{\mathrm{S}}$ layers increase, spanning a larger vertical extent during the solstices. In general, the $E_{\mathrm{s}}$ intensity exceeding 0.65 values is distributed at altitudes of $100-125 \mathrm{~km}$ in the southern summer and at altitudes of $90-130 \mathrm{~km}$ in the northern summer. During equinox seasons, the $E_{\mathrm{s}}$ intensity is moderate and its altitude-latitude distribution is relatively symmetrical.

\section{Wind shear explanation for $E_{\mathrm{s}}$ seasonal variation}

The global climatology of the intensity of $E_{\mathrm{S}}$ layers is investigated from the COSMIC occultation data, employing the GPS-RO technique. One of the pronounced variabilities in $E_{\mathrm{s}}$ layers is the seasonal variation, with a maximum appearance in the summer hemisphere. Although the mechanism for $E_{\mathrm{s}}$ layer formation is widely accepted, these dense and thin layers of metallic ion plasma are formed by the vertical ion convergence of neutral wind shear. The overall morphology of $E_{\mathrm{s}}$ layers cannot be explained by the wind shear. One of the unsolved issues in the ionosphere is that the overall morphology, including the seasonal dependence of $E_{\mathrm{s}}$ layers, does not have a comprehensive explanation (Whitehead, 1989; Haldoupis et al., 2007).

Seasonal dependence is found not only in the $E_{\mathrm{s}}$ intensity but also in previous studies of $E_{\mathrm{S}} \mathrm{OR}$ variations (Wu et al., 2005; Arras et al., 2008; Chu et al., 2014). Chu et al. (2014) simulated the global distribution of the convergence of metallic ion flux caused by vertical wind shear, suggesting that the maximum $E_{\mathrm{s}}$ in summer and minimum of $E_{\mathrm{s}}$ in winter are likely caused by the vertical wind shear effect. 


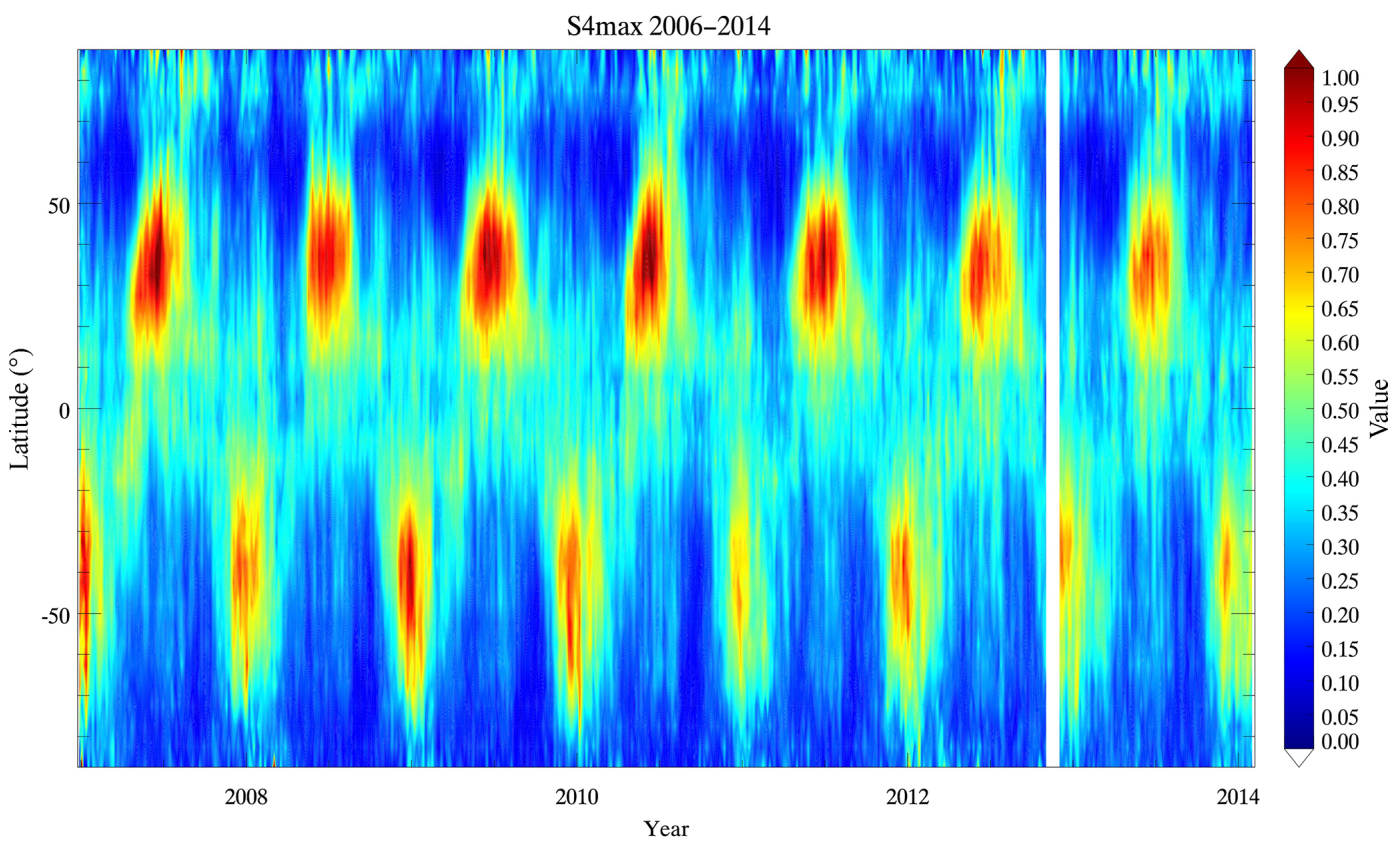

Figure 3. Time series of $E_{\mathrm{S}}$ intensity with a resolution of $5^{\circ}$ latitude $\times 5$ days for the period from December 2006 to January 2014 .

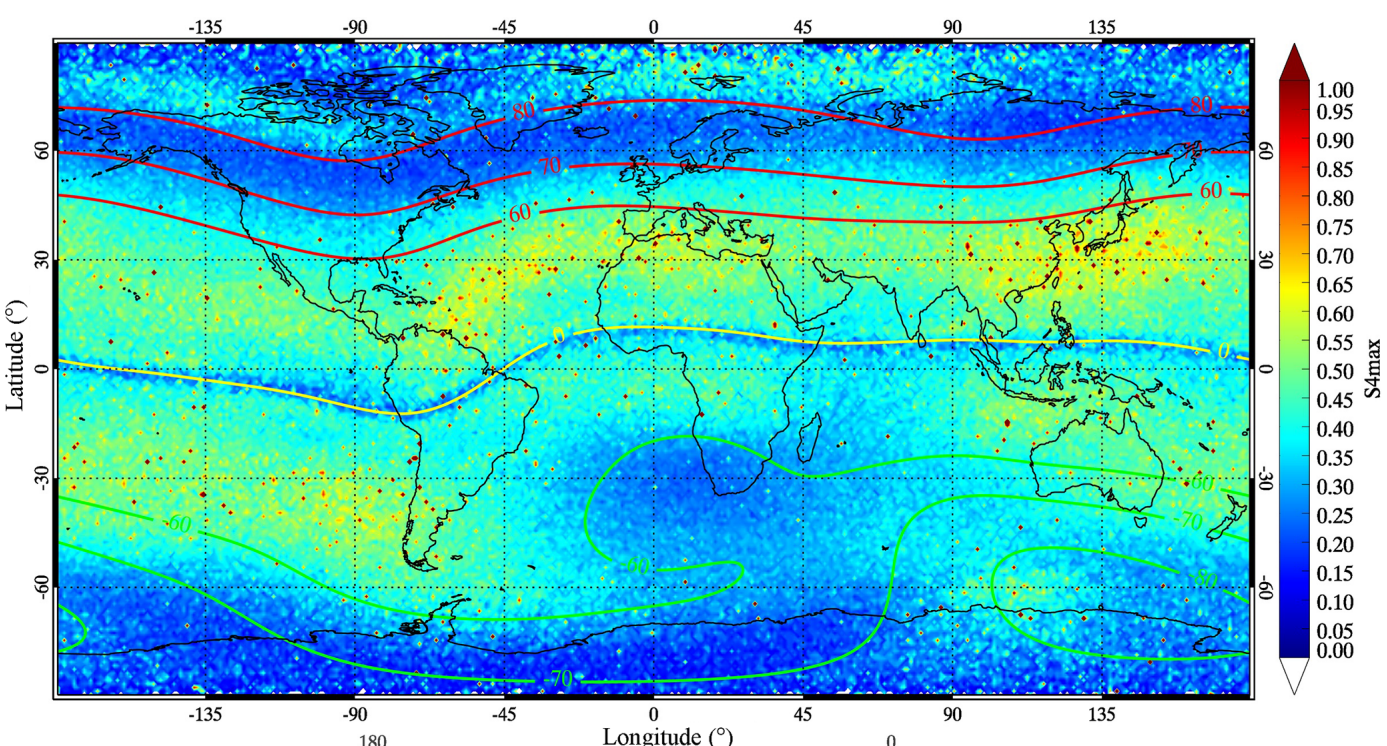

North
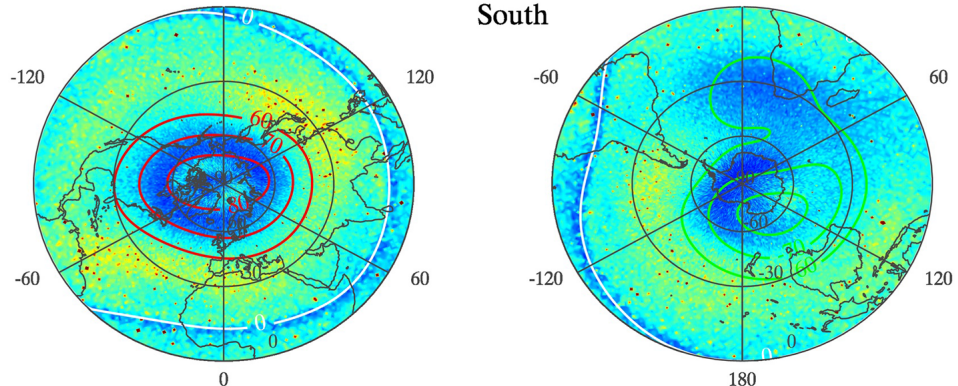

Figure 4. Global geographical distributions of the $E_{\mathrm{S}}$ average intensity from 2006 to 2014 , with the spatial resolution of a $1^{\circ} \times 1^{\circ}$ grid. The red and green curves signify the geomagnetic latitude contours of 60,70 , and $80^{\circ}$, and the yellow curve represents the geomagnetic equator. 
(a)

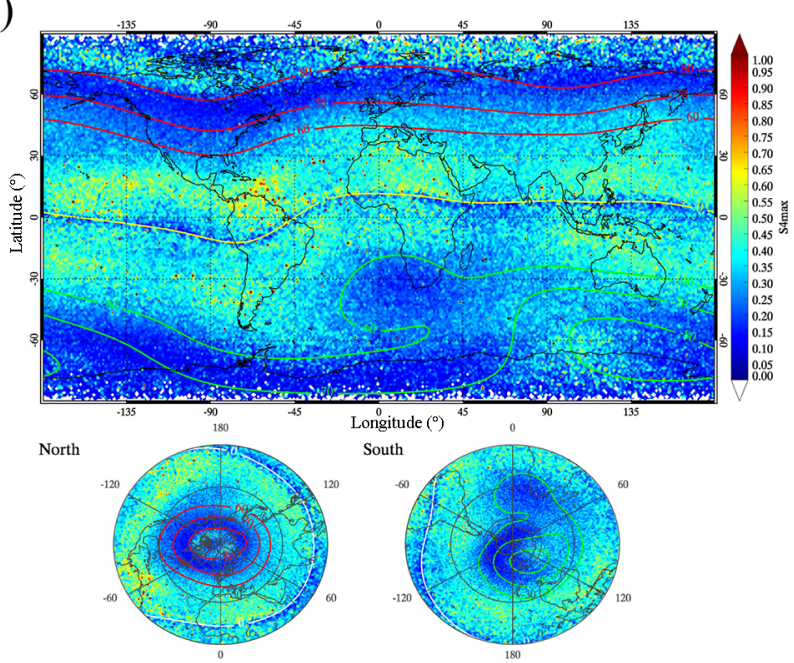

(c)

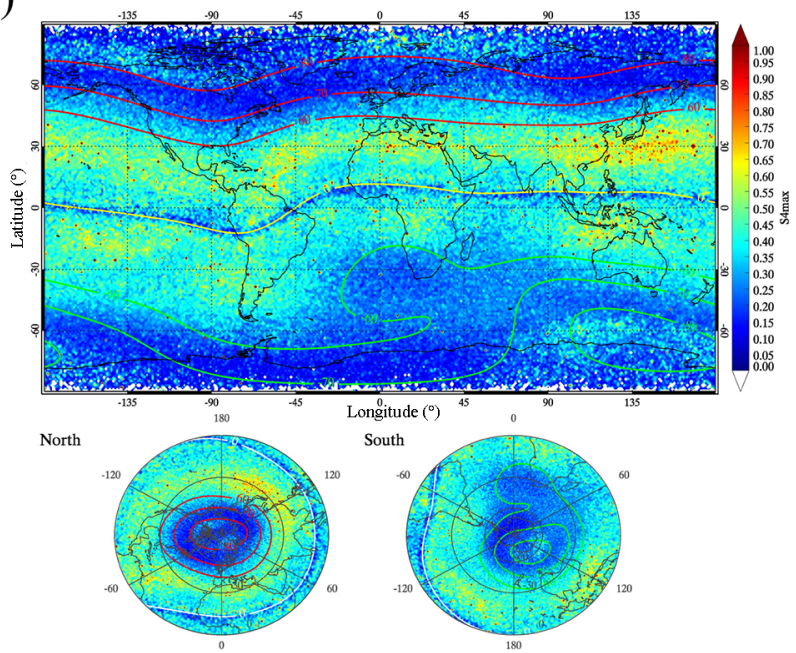

(b)

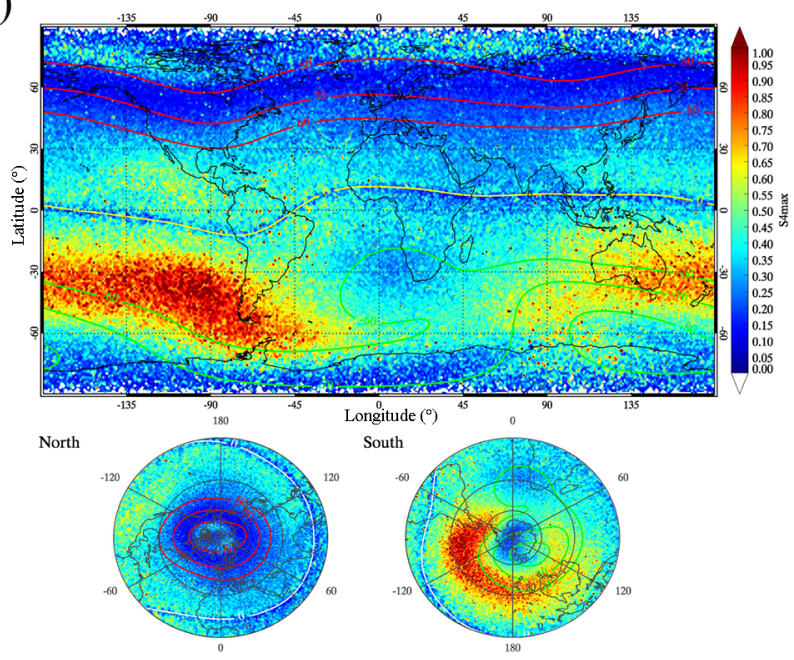

(d)

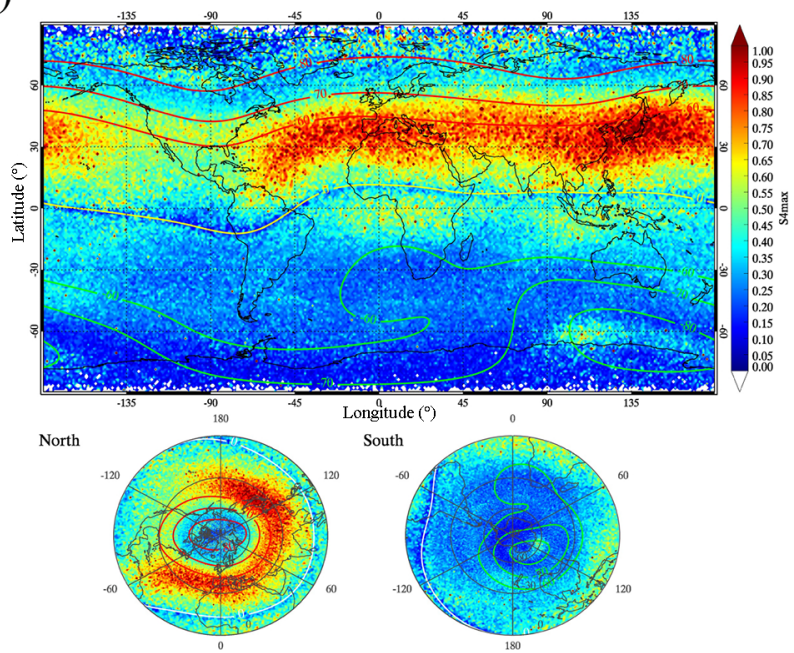

Figure 5. Seasonal variations in $E_{\mathrm{S}}$ intensity from 2006 to 2014, with the spatial resolution of a $1^{\circ} \times 1^{\circ}$ grid. Plots for (a) autumn (September, October, November), (b) winter (December, January, February), (c) spring (March, April, May), and (d) summer (June, July, August).

From the wind shear (e.g. Nygren et al., 1984; Mathews, 1998; Kirkwood and Nilsson, 2000), the vertical ion velocity $w_{\mathrm{i}}$ induced by the neutral wind is described by Eq. (1):

$w_{\mathrm{i}}=\frac{r_{\mathrm{i}} \cos I}{1+r_{\mathrm{i}}^{2}} \times U-\frac{\sin I \cos I}{1+r_{\mathrm{i}}^{2}} \times V+\frac{r_{\mathrm{i}}^{2}+\sin ^{2} I}{1+r_{\mathrm{i}}^{2}} \times W$,

where $I$ represents the magnetic inclination angle that is defined as positive (i.e. downward direction) in the Northern Hemisphere; $r_{1}$ represents the ratio of the ion-neutral collision frequency $\left(\nu_{\mathrm{i}}\right)$ to the ion gyrofrequency $\left(\omega_{\mathrm{i}}\right)$; and the neutral wind velocity $V_{\mathrm{n}}=(U, V, W)$ components are in the zonal (positive for eastward), meridional (positive for northward), and vertical (positive for upward) directions. Therefore, the favourable wind field for $E_{\mathrm{s}}$ layer formation is where there is a negative $\frac{\mathrm{d} w_{\mathrm{i}}}{\mathrm{d} z}$ relationship, indicating an ionconvergence region.
Version 4 of the WACCM (WACCM4) is a global climate model with interactive chemistry, developed at the National Center for Atmospheric Research (NCAR) (Marsh et al., 2013). A specified dynamics run of WACCM4 (SDWACCM4) was constrained by the Modern-Era Retrospective Analysis for Research and Applications (MERRA). SDWACCM4 is used to simulate the global distribution of the divergence of ion velocity from the period of 2006 to 2014, which is consistent with the period of $E_{\mathrm{S}}$ observations from the COSMIC occultation data. To compare with previous studies, the neutral wind is provided by the output from WACCM, and the ion-neutral frequency is calculated by the atmospheric composition from the MSIS-00 atmospheric model in accordance with Chu et al. (2014). The global distributions of the geomagnetic field and magnetic inclination angle at $100 \mathrm{~km}$ are estimated from the IGRF-12 model. The calculation of ion velocity is binned and averaged in a $1^{\circ}$ lat- 


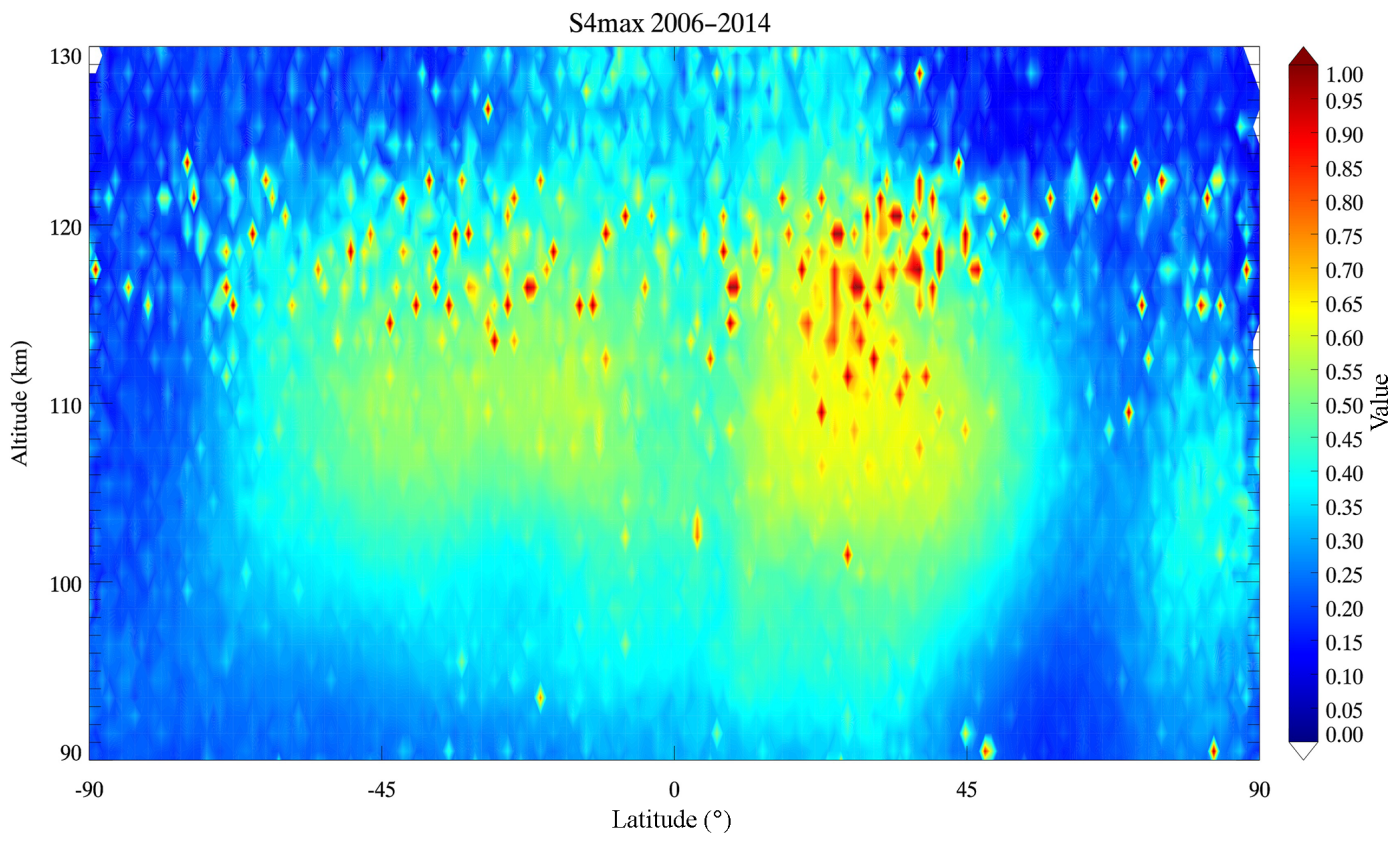

Figure 6. Altitude-latitude distribution of the $E_{\mathrm{S}}$ intensity from 2006 to 2014 , with a resolution of $1 \mathrm{~km}$ altitude $\times 1^{\circ}$ latitude.

(a)

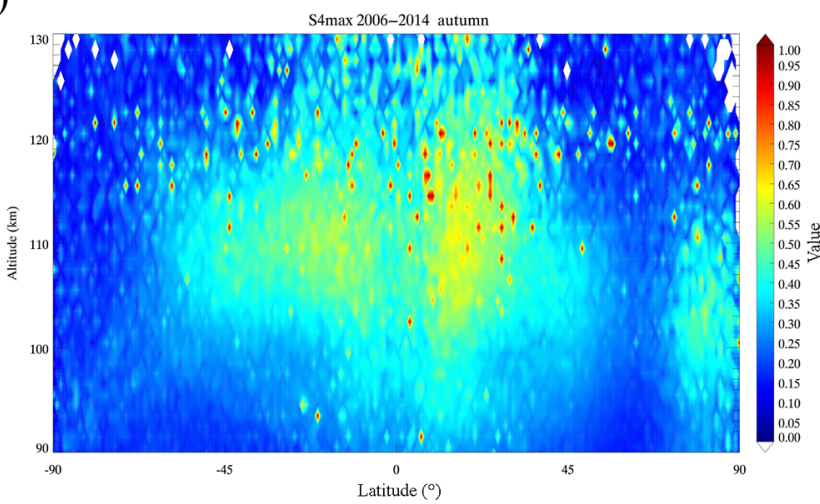

(c)

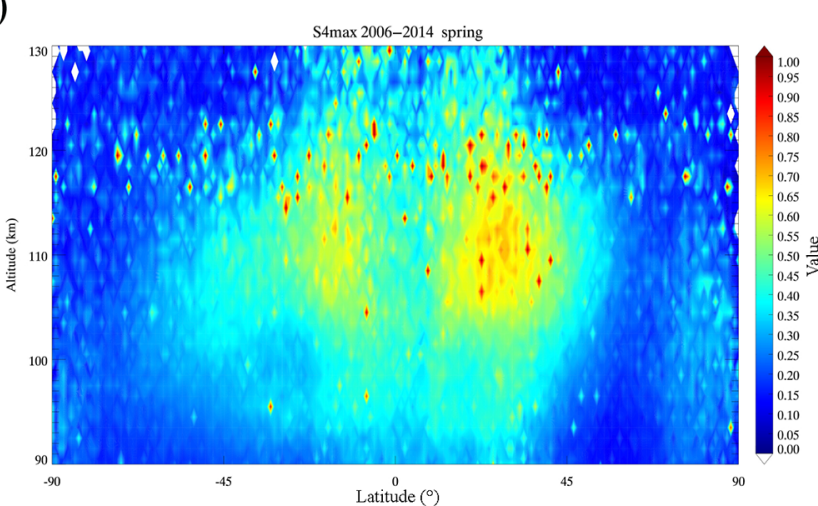

(b)

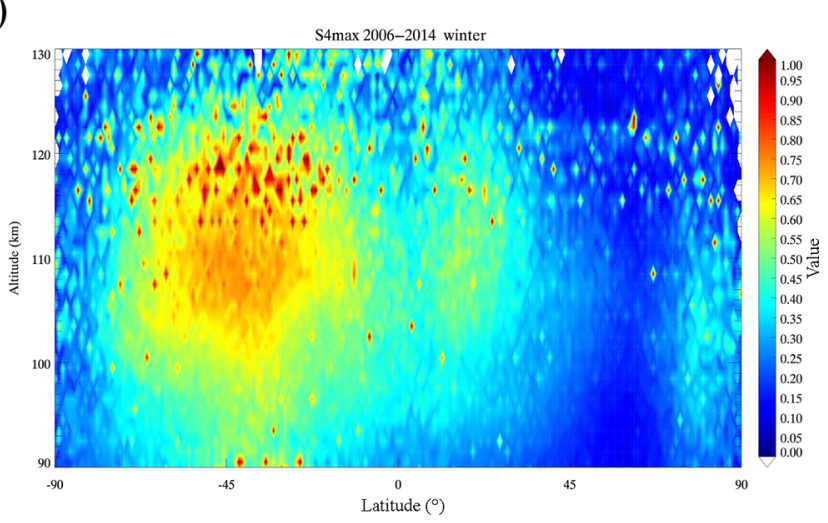

(d)

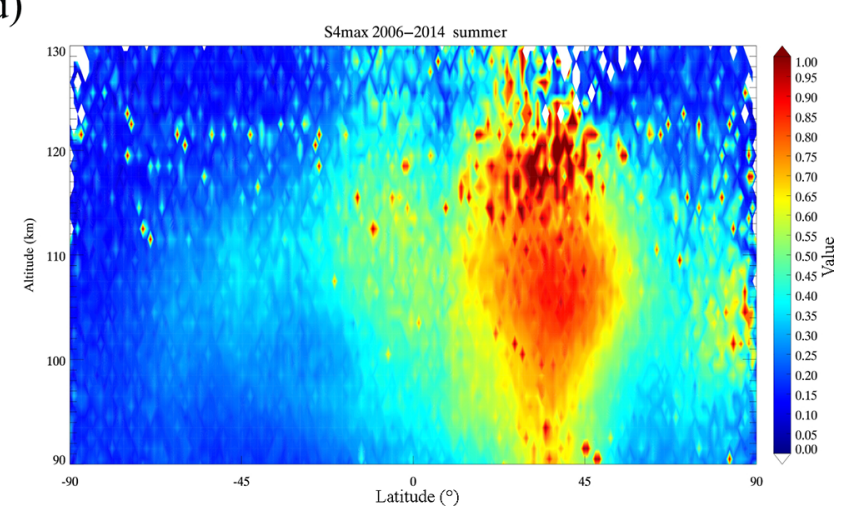

Figure 7. Seasonal variations in altitude-latitude distributions of $E_{\mathrm{S}}$ intensity from 2006 to 2014 for four different seasons: (a) autumn, (b) winter, (c) spring, and (d) summer. 
itude $\times 1^{\circ}$ longitude grid at WACCM altitude levels from 0 to $130 \mathrm{~km}$.

Figure 8 presents simulation results of the global distributions of the monthly mean divergence in vertical ion velocity in the altitude range between 97 and $114 \mathrm{~km}$ in January and July. The negative (positive) $\frac{\mathrm{d} w_{\mathrm{i}}}{\mathrm{d} z}$ ratio represents the convergence (divergence) of ions in units of $\mathrm{m} \mathrm{s}^{-1} \mathrm{~km}^{-1}$. The results show a good correlation between the simulated distributions of the monthly mean divergence of vertical ion velocity in Fig. 8 and the geographical distribution of $E_{\mathrm{S}}$ intensity measured from the COSMIC GPS-RO profiles in Fig. 5. Chu et al. (2014) simulated the global distributions of the mean divergence of the $\mathrm{Fe}^{+}$concentration flux at altitudes of $94-115 \mathrm{~km}$ in all four seasons. The study also showed a similar simulation result for the distributions of divergence in the $\mathrm{Fe}^{+}$concentration flux, which is well correlated with the COSMIC-measured $E_{\mathrm{S}} \mathrm{OR}$ distribution. The simulation of the divergence of vertical ion velocity supports the wind shear of $E_{\mathrm{s}}$ formation and indicates that the seasonal dependence of $E_{\mathrm{s}}$ layers is likely attributed to the convergence of vertical ion velocity driven by neutral wind.

Furthermore, we also notice that the $E_{\mathrm{s}}$ intensity is distributed at relatively high altitudes of 95-125 km compared with the $E_{\mathrm{S}} \mathrm{OR}$ at $90-120 \mathrm{~km}$. The densest patches of $E_{\mathrm{s}}$ exist above $115 \mathrm{~km}$, and the $E_{\mathrm{s}}$ layer has a broader vertical extent in summer, as shown in Fig. 7. In the simulation, the distributions of the monthly mean divergence of the vertical ion velocity at an altitude range of $114-128 \mathrm{~km}$ in January and July are shown in Fig. 9. In contrast with the distributions of the divergence of vertical ion velocity between 97 and $114 \mathrm{~km}$ in Fig. 8, Fig. 9 shows an ion-divergence region at altitudes of $114-128 \mathrm{~km}$ in summer over mid-latitudes as a result of different zonal and meridional winds. These results suggest that the wind shear alone has difficulty explaining the $E_{\mathrm{s}}$ seasonal dependence at higher altitudes (114-128 km), although the wind shear is considered the primary theory for explaining the physical production of $E_{\mathrm{S}}$ layers (Whitehead, 1989; Haldoupis et al., 2007).

In previous studies on the wind shear of $E_{\mathrm{s}}$ layer formation, the magnetic declination angle effect is neglected in the calculation of the vertical ion velocity $w_{\mathrm{i}}$ induced by the neutral wind. The steady-state ion momentum equation is as follows:

$m_{\mathrm{i}} \frac{\mathrm{d} \boldsymbol{v}_{\mathrm{i}}}{\mathrm{d} t}=0=e\left(\boldsymbol{E}+\boldsymbol{v}_{\mathrm{i}} \times \boldsymbol{B}\right)-m_{\mathrm{i}} v_{\mathrm{in}}\left(\boldsymbol{v}_{\mathrm{i}}-\boldsymbol{V}_{\mathrm{n}}\right)$.

On the basis of the steady-state ion momentum equation, the Eq. (1) for the vertical ion velocity $w_{\mathrm{i}}$ is extended to take the magnetic declination angle $D$ into consideration as follows:

$w_{\mathrm{i}}=\frac{r_{\mathrm{i}} \cos D \cos I-\sin D \sin I \cos I}{1+r_{\mathrm{i}}^{2}} \times U$

$$
\begin{aligned}
& -\frac{r_{\mathrm{i}} \sin D \cos I+\cos D \sin I \cos I}{1+r_{\mathrm{i}}^{2}} \times V \\
& +\frac{r_{\mathrm{i}}^{2}+\sin ^{2} I}{1+r_{\mathrm{i}}^{2}} \times W .
\end{aligned}
$$

The magnetic declination angle currently ranges from $-30^{\circ} \mathrm{W}$ to $26^{\circ} \mathrm{E}$; therefore, it is expected to have an influence on the vertical ion velocity $w_{i}$. The effect of the magnetic declination angle on the divergence in ion velocity in the simulation of $E_{\mathrm{S}}$ is investigated. Figure 10 presents the global distributions of the monthly mean divergence in vertical ion velocity at altitudes ranging from 97 to $114 \mathrm{~km}$ with the consideration of the magnetic declination angle. The figure shows a seasonal dependence, with ion-convergence regions in summer and ion-divergence regions in winter. However, the morphology of the divergence of the vertical ion velocity is different from that without the magnetic declination angle considered in Fig. 8. In January, strong ion convergence appears in the SAA region. In July, Asia, Europe, and the North Pacific tend to be regions of ion convergence. The agreement with the observations becomes worse, which could imply that the cause of global $E_{\mathrm{s}}$ layers remains a mystery because it cannot be fully accounted for by the wind shear effect (Whitehead, 1989; Haldoupis et al., 2007). The formation of mid-latitude $E_{\mathrm{s}}$ layers could be partially explained by the wind shear. The investigation of the causes of seasonal variability in $E_{\mathrm{s}}$ should lead to more detailed studies so that we can fully understand and properly quantify the properties of $E_{\mathrm{s}}$ layers.

\section{Discussion}

The seasonal and geographical dependences of $E_{\mathrm{s}} \mathrm{OR}$ have been widely studied by ionospheric observations since the 1960s (Leighton et al., 1962; Smith, 1978; Wu et al., 2005; Arras et al., 2008; Zeng and Sokolovskiy, 2010), but, thus far, the overall morphology of $E_{\mathrm{s}}$ is still not well explained. The seasonal dependence of $E_{\mathrm{s}}$ layers remains an ongoing mystery, as it is unexpected in the classical wind shear reported in the review article of Whitehead (1989). Recently, Chu et al. (2014) simulated the distribution of the convergence of the $\mathrm{Fe}^{+}$concentration flux and indicated that the vertical ion convergence caused by neutral wind could be responsible for the seasonal dependence of $E_{\mathrm{s}}$.

In our investigations, the global climatology of the intensity of $E_{\mathrm{s}}$ layers is found to also have a seasonal dependence, with a pronounced maximum over mid-latitudes in the summer hemisphere, as shown in Fig. 5. The $E_{\mathrm{s}}$ intensity has similar seasonal and spatial distributions to the $E_{\mathrm{s}} \mathrm{OR}$, but the $E_{\mathrm{S}}$ layer has a relatively large intensity and a small $E_{\mathrm{s}} \mathrm{OR}$ value at the North Pole and South Pole. The wind shear mechanism does not work efficiently at either auroral zones or the magnetic equator (Haldoupis, 2012); therefore, the strong $E_{\mathrm{s}}$ layers in the Earth's polar regions could 
(a)

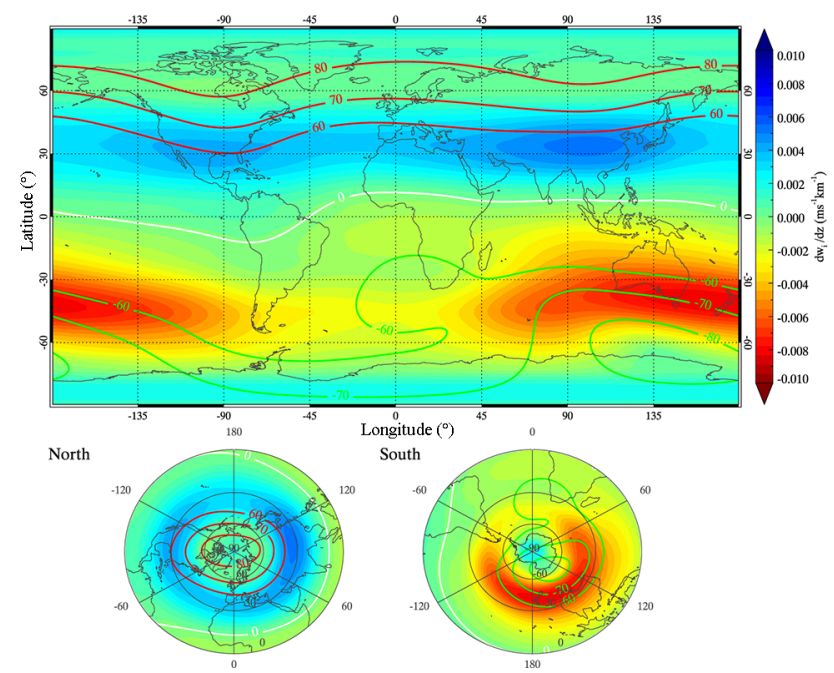

(b)

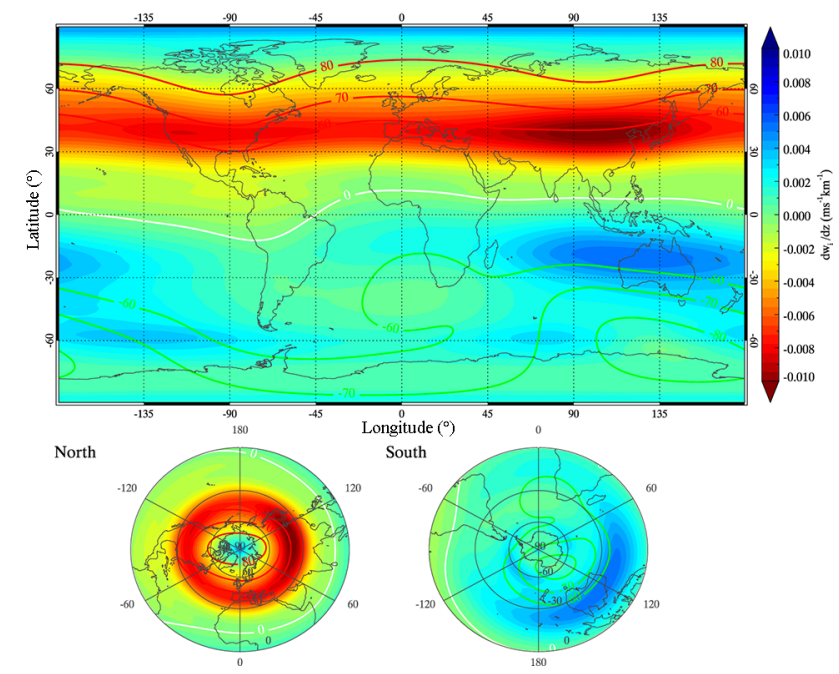

Figure 8. Simulation results of the global distributions of the monthly mean divergence of vertical ion velocity from 2006 to 2014 (units of $\mathrm{m} \mathrm{s}^{-1} \mathrm{~km}^{-1}$ ) at altitudes ranging between 97 and $114 \mathrm{~km}$ in January (a) and July (b). The red and green curves signify 60,70 , and $80^{\circ}$ geomagnetic latitude contours, and the yellow curve represents the geomagnetic equator.

(a)

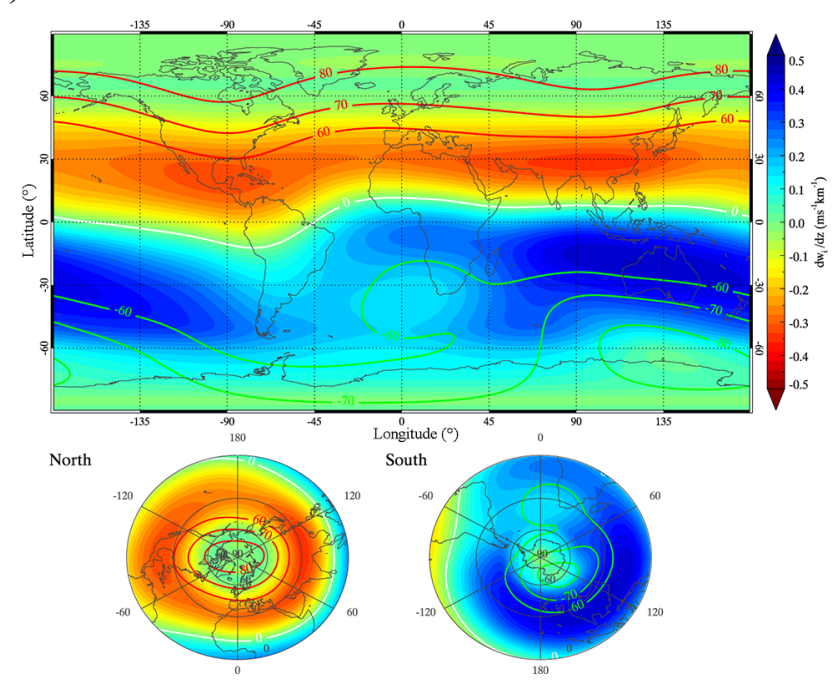

(b)

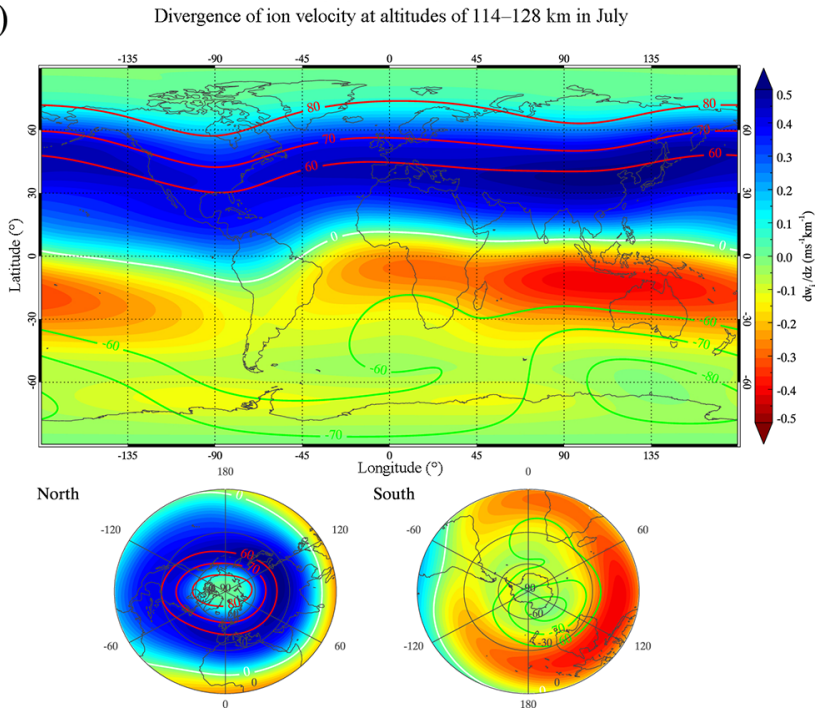

Figure 9. Same as Fig. 8 but for the altitude range between 114 and $128 \mathrm{~km}$ in January (a) and July (b).

be initially caused by gravity waves (Bautista et al., 1998; MacDougall et al., 2000a, b). In the simulations, the gravity waves with horizontal wavelengths smaller than $\sim 200 \mathrm{~km}$ are not explicitly resolved in WACCM (Liu et al., 2014). In particular, the vertical motion of gravity waves dominates the formation of the $E_{\mathrm{s}}$ layer on the polar cap, where the nearvertical magnetic field significantly reduces the effectiveness of wind-shear in converging ions into layers. Polar-cap gravity waves have been studied by Johnson et al. (1995) and MacDougall et al. (1997). These layers are maintained in an ionised state through charge exchange of neutral metal atoms with $\mathrm{NO}^{+}$and $\mathrm{O}_{2}^{+}$ions by photoionisation. These studies found that the vertical motion of gravity waves is very efficient in concentrating polar-cap $E_{\mathrm{s}}$ layers. The short-lived polar-cap $E_{\mathrm{s}}$ layers in winter appear to be associated with gravity waves. In summer the polar-cap $E_{\mathrm{s}}$ layers are longlasting and thin. These initial concentrations of metallic ions persist and change into long-lived $E_{\mathrm{s}}$ because of ambient metallic ions produced by photoionisation in the sunlit $E$ region (MacDougall et al., 2000a). The $E_{\mathrm{s}}$ layers at the cusp latitude are relatively different from those at the polar cap. The cusp $E_{\mathrm{s}}$ could be associated with the convergence of ionisation by the electric fields (MacDougall and Jayachandran, 2005). 
(a)

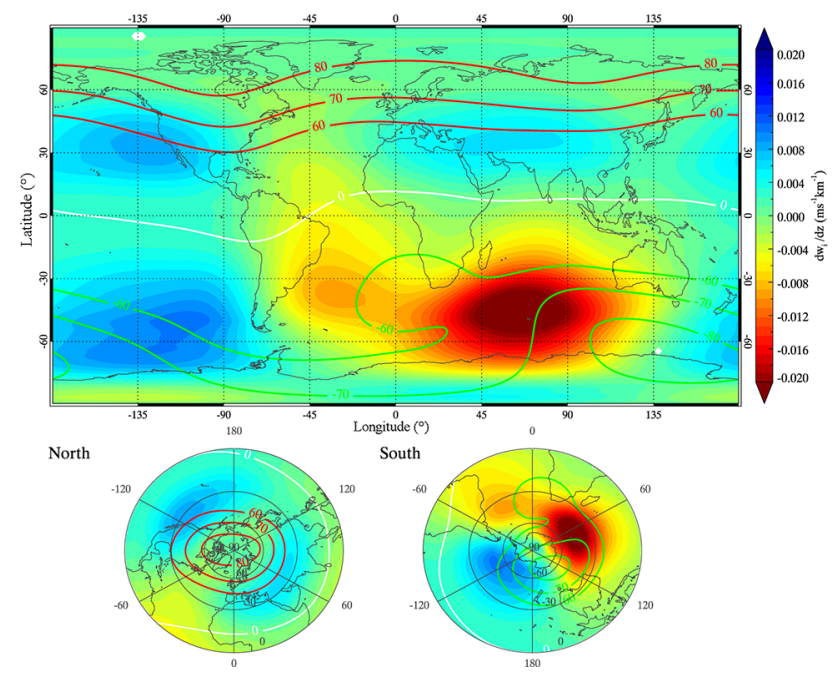

(b)

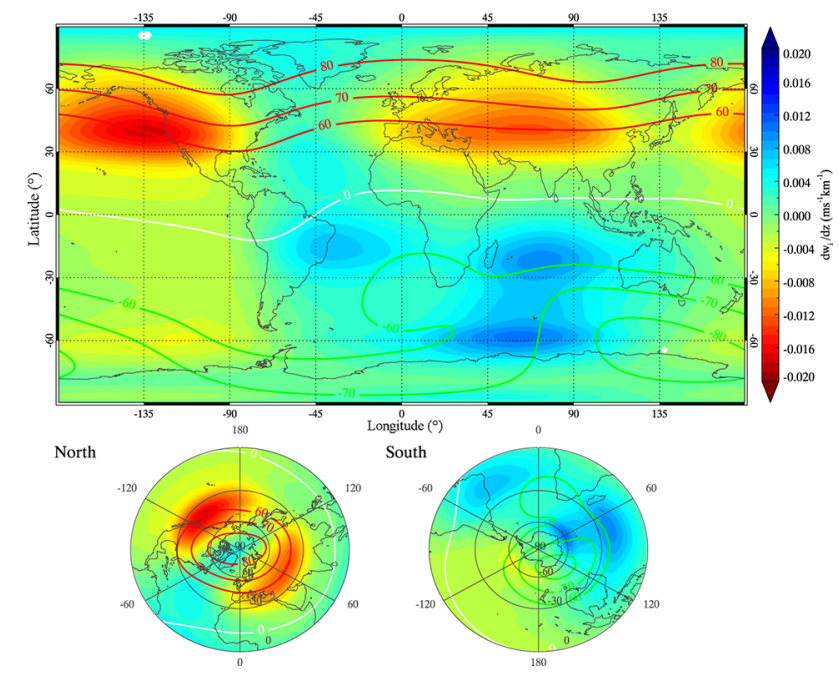

Figure 10. Same as Fig. 8 but with the consideration of the effect of the magnetic declination angle on the vertical ion velocity in January (a) and July (b).

On the other hand, simulating the global distributions of the monthly mean divergence of vertical ion velocity in an altitude range between 97 and $114 \mathrm{~km}$ shows an ionconvergence region in the summer mid-latitudes, which is similar to the simulation results of Chu et al. (2014). This result suggests that the seasonal dependence of $E_{\mathrm{s}}$ is likely attributed to the vertical convergence of ions driven by neutral wind. However, some disagreements between the distributions of the calculated divergence of vertical ion velocity and observed $E_{\mathrm{s}}$ intensity are found. For example, there are iondivergence regions in the mid-latitudes in winter in Fig. 8, but the dissipation of $E_{\mathrm{s}}$ is observed in the $60-80^{\circ}$ geomagnetic latitude band. The densest $E_{\mathrm{s}}$ layer appears above $115 \mathrm{~km}$, which is higher than the $E_{\mathrm{S}} \mathrm{OR}$. Another discrepancy is that the simulated divergence of vertical ion velocity in an altitude range between 114 and $128 \mathrm{~km}$ has a positive $\frac{\mathrm{d} w_{\mathrm{i}}}{\mathrm{d} z}$ ratio in the summer hemisphere, which indicates an ion-divergence region of ions in contrast with the observed summer maximum of $E_{\mathrm{s}}$ intensity in the summer mid-latitudes.

The effect of the magnetic declination angle on the divergence of metallic ion velocity is investigated in the simulation of $E_{\mathrm{s}}$ for the first time in Fig. 10. Though the figure shows marked seasonal dependence, with a strong summer ion-convergence region, the morphology of the divergence of vertical ion velocity is different from the distribution of the observed $E_{\mathrm{s}}$ intensity in Fig. 5. Thus, the vertical ion convergence by itself is far from sufficient for explaining the strong $E_{\mathrm{s}}$ summer maximum. Other physical processes should also be considered in the geographical distribution and spatial variations in $E_{\mathrm{s}}$ layers, as they play important roles in determining the global morphology of $E_{\mathrm{s}}$, such as the magnetic field, ionospheric electric field, the chemical processes of metallic ions, large geomagnetic storms, and meteorolog- ical processes in the lower atmosphere (e.g. Bautista et al., 1998; Mathews, 1998; Carter and Forbes, 1999; MacDougall et al., 2000a, b; Davis and Johnson, 2005; MacDougall and Jayachandran, 2005; Johnson and Davis, 2006; Haldoupis, 2012; Yue et al., 2012; Feng et al., 2013; Yu et al., 2015).

Haldoupis et al. (2007) proposed that the seasonal dependence of $E_{\mathrm{s}}$ could be explained by the seasonal variation in the meteor influx into the upper atmosphere. However, it has been largely accepted that sporadic meteoroids provide a much greater meteor mass on average than meteor showers (Ceplecha et al., 1998; Baggaley, 2002; Janches et al., 2002; Williams and Murad, 2002). The meteoric mass influx caused by sporadic meteoroids reaches a maximum in autumn rather than summer (Janches et al., 2006). The global input of meteoric material is well established to enhance the mesospheric metal layers and $E_{\mathrm{s}}$ layers (Plane, 2004; Plane et al., 2015). Carrillo-Sánchez et al. (2016) estimated the global interplanetary dust particles (IDPs) to be $43 \pm 14 \mathrm{td}-1$; this was taken from three different observations in order to constrain the relative contributions of each dust source to lidar observations of the vertical $\mathrm{Na}$ and $\mathrm{Fe}$ fluxes. However, the daily amount is still not well defined. Estimates of the IDP range from 5 to $270 \mathrm{td}-1$, depending on the different methods used to make the estimate (Plane, 2012). These effects of meteoric ablation are significantly influenced by the magnitude of the IDP input with 2 orders of magnitude uncertainty. On the other hand, this fact also highlights the importance of a fundamental understanding of the global climatology of $E_{\mathrm{s}}$ layers. 


\section{Conclusions}

In this study, we investigate the long-term climatology of the intensity of $E_{\mathrm{S}}$ layers on the basis of S4max data retrieved from COSMIC GPS-RO measurements. The resulting global $E_{\mathrm{s}}$ maps with a high spatial resolution present the geographical distributions and strong seasonal dependence of $E_{\mathrm{s}}$ intensity, which agrees with former studies of global $E_{\mathrm{s}} \mathrm{OR}$ maps (Wu, 2006; Arras et al., 2008; Chu et al., 2014). The high $E_{\mathrm{s}}$ intensity in summer exists at altitudes of $115-125 \mathrm{~km}$ at 10 $60^{\circ}$ latitude in the Northern Hemisphere and at altitudes of $115-120 \mathrm{~km}$ at $10-75^{\circ}$ latitudes in the Southern Hemisphere.

Furthermore, the simulation results of the global distributions of the monthly mean divergence of vertical ion velocity could partially explain the seasonal dependence of $E_{\mathrm{s}}$ intensity. We show that the elemental mechanism responsible for $E_{\mathrm{S}}$ layers based on wind shear could explain the seasonal dependence of $E_{\mathrm{s}}$ intensity (97-114 km), but it is hard to explain the $E_{\mathrm{S}}$ seasonal dependence at higher altitudes (114$128 \mathrm{~km})$. To further investigate the magnetic-field effects on the wind shear processes of $E_{\mathrm{s}}$ formation, the effect of the magnetic declination angle on the divergence of metallic ion velocity in the simulation of $E_{\mathrm{S}}$ is investigated, and we discuss some disagreements between the distributions of the calculated divergence of vertical ion velocity and the observed $E_{\mathrm{s}}$ intensity. Although the wind shear of $E_{\mathrm{s}}$ formation was conceived and formulated in the 1960s (Whitehead, 1961), its importance for understanding the formation of $E_{\mathrm{s}}$ must have escaped attention. This study implies that, in addition to the vertical wind shear effects, other processes, such as the vertical motion of gravity waves, magnetic-field effects, meteoric mass influx into Earth's atmosphere, and the chemical processes of metallic ions, should also be considered, which could play a dominant role in the geographical and seasonal variations in $E_{\mathrm{S}}$ layers. To accurately understand and properly quantify the properties of $E_{\mathrm{s}}$ layers on a global scale that are also associated with the distribution of global metallic ions, we need to combine more ground-based ionosonde data with satellite observations and extensively study the geographical and seasonal variations in $E_{\mathrm{s}}$ layers.

Data availability. The COSMIC global data sets are downloaded from https://cdaac-www.cosmic.ucar.edu/cdaac/ (last access: 30 December 2017).

Author contributions. BY and XX designed the study and wrote the manuscript. XY provided the COSMIC radio occultation data and contributed significantly to the comments on an early version of the manuscript. CY and CY discussed the results of the wind shear simulation. BN and LH provided the manually scaled ionospheric observation from Beijing. XD contributed to the discussion of the results and the preparation of the manuscript. All authors discussed the results and commented on the manuscript at all stages.
Competing interests. The authors declare that they have no conflict of interest.

Special issue statement. This article is part of the special issue "Layered phenomena in the mesopause region (ACP/AMT interjournal SI)". It is a result of the LPMR workshop 2017 (LPMR2017), Kühlungsborn, Germany, 18-22 September 2017.

Acknowledgements. We acknowledge the COSMIC (Constellation Observing System for Meteorology, Ionosphere, and Climate) radio occultation data, the ionosonde data from the Chinese Meridian Project, the Solar-Terrestrial Environment Research Network (STERN), the Data Center for Geophysics, Data Sharing Infrastructure of Earth System Science, and the National Science \& Technology Infrastructure of China, as well as the Whole Atmosphere Community Climate Model (WACCM), NRL Mass Spectrometer and Incoherent Scatter (MSIS)-00 atmospheric model, and International Geomagnetic Reference Field (IGRF)-12 geomagnetic field model data used in this paper. This work is supported by the National Natural Science Foundation of China (41774158, 41474129, $41421063,41804147)$, the open research project of CAS Large Research Infrastructures, the Youth Innovation Promotion Association of the Chinese Academy of Sciences (2011324), Anhui Provincial Natural Science Foundation (1908085QD155) and the Fundamental Research Fund for the Central Universities. Bingkun Yu is also supported by a Newton International Fellowship from the Royal Society.

Review statement. This paper was edited by Bernd Funke and reviewed by three anonymous referees.

\section{References}

Arras, C., Wickert, J., Beyerle, G., Heise, S., Schmidt, T., and Jacobi, C.: A global climatology of ionospheric irregularities derived from GPS radio occultation, Geophys. Res. Lett., 35, L14809, https://doi.org/10.1029/2008GL034158, 2008.

Baggaley, W. J.: Radar observations, Cambridge University Press, Cambridge, 2002.

Bautista, M. A., Romano, P., and Pradhan, A. K.: Resonanceaveraged photoionization cross sections for astrophysical models, Astrophys. J. Suppl. S., 118, 259-265, 1998.

Carrillo-Sánchez, J. D., Plane, J. M. C., Feng, W., Nesvorn, D., and Janches, D.: On the size and velocity distribution of cosmic dust particles entering the atmosphere, Geophys. Res. Lett., 42, 65186525, 2015.

Carrillo-Sánchez, J. D., Nesvorn, D., Pokorn, P., Janches, D., and Plane, J. M. C.: Sources of cosmic dust in the Earth's atmosphere, Geophys. Res. Lett., 43, 11979-11986, https://doi.org/10.1002/2016GL071697, 2016.

Carter, L. N. and Forbes, J. M.: Global transport and localized layering of metallic ions in the upper atmosphere, Ann. Geophys., 17, 190-209, 1999. 
Ceplecha, Z., Borovička, J., Elford, W. G., ReVelle, D. O., Hawkes, R. L., Porubčan, V., and Šimek, M.: Meteor phenomena and bodies, Space Sci. Rev., 84, 327-471, 1998.

Chu, Y., Wang, C., Wu, K., Chen, K., Tzeng, K. J., Su, C., Feng, W., and Plane, J. M. C.: Morphology of sporadic $E$ layer retrieved from COSMIC GPS radio occultation measurements: Wind shear theory examination, J. Geophys. Res.-Space, 119, 2117-2136, 2014.

Chu, Y.-H. and Wang, C.-Y.: Interferometry observations of threedimensional spatial structures of sporadic $E$ irregularities using the Chung-Li VHF radar, Radio Sci., 32, 817-832, 1997.

Chu, Y.-H., Brahmanandam, P. S., Wang, C.-Y., Su, C.-L., and Kuong, R.-M.: Coordinated sporadic $E$ layer observations made with Chung-Li $30 \mathrm{MHz}$ radar, ionosonde and FORMOSAT3/COSMIC satellites, J. Atmos. Sol.-Terr. Phy., 73, 883-894, 2011.

Davis, C. J. and Johnson, C. G.: Lightning-induced intensification of the ionospheric sporadic $E$ layer, Nature, 435, 799-801, https://doi.org/10.1038/nature03638, 2005.

Farley, D. T.: Theory of equatorial electrojet plasma waves-new developments and current status, J. Atmos. Terr. Phys., 47, 729744, 1985

Feng, W., Marsh, D. R., Chipperfield, M. P., Janches, D., Höffner, J., Yi, F., and Plane, J. M. C.: A global atmospheric model of meteoric iron, J. Geophys. Res.-Atmos., 118, 9456-9474, 2013.

Grebowsky, J. M. and Aikin, A.: In situ measurements of meteoric ions, in: Meteors in the Earth's Atmosphere, edited by: Murad, E. and Williams, I. P., 189-214, Cambridge Univ. Press, UK, 2002.

Haldoupis, C.: Midlatitude sporadic E. A typical paradigm of atmosphere-ionosphere coupling, Space Sci. Rev., 168, 441-461, 2012.

Haldoupis, C., Pancheva, D., Singer, W., Meek, C., and MacDougall, J.: An explanation for the seasonal dependence of midlatitude sporadic $E$ layers, J. Geophys. Res.-Space, 112, A06315, https://doi.org/10.1029/2007JA012322, 2007.

Hocke, K. and Tsuda, T.: Gravity waves and ionospheric irregularities over tropical convection zones observed by GPS/MET radio occultation, Geophys. Res. Lett., 28, 2815-2818, 2001.

Janches, D., Pellinen-Wannberg, A., Wannberg, G., Westman, A., Häggström, I., and Meisel, D. D.: Tristatic observations of meteors using the $930 \mathrm{MHz}$ European Incoherent Scatter radar system, J. Geophys. Res.-Space, 107, 14-1, https://doi.org/10.1029/2001JA009205, 2002.

Janches, D., Heinselman, C. J., Chau, J. L., Chandran, A., and Woodman, R.: Modeling the global micrometeor input function in the upper atmosphere observed by high power and large aperture radars, J. Geophys. Res.-Space, 111, A07317, https://doi.org/10.1029/2006JA011628, 2006.

Johnson, C. G. and Davis, C. J.: The location of lightning affecting the ionospheric sporadic- $E$ layer as evidence for multiple enhancement mechanisms, Geophys. Res. Lett., 33, L07811, https://doi.org/10.1029/2005GL025294, 2006.

Johnson, F. S., Hanson, W. B., Hodges, R. R., Coley, W. R., Carignan, G. R., and Spencer, N. W.: Gravity waves near $300 \mathrm{~km}$ over the polar caps, J. Geophys. Res.-Space, 100, 23993-24002, 1995.

Kelley, M. C.: The Earth's Ionosphere, Int. Geophys. Ser., 43, 71, Academic, San Diego, Calif., 1989.
Kirkwood, S. and Nilsson, H.: High-latitude sporadic- $E$ and other thin layers-the role of magnetospheric electric fields, Space Sci. Rev., 91, 579-613, 2000.

Ko, C. P. and Yeh, H. C.: COSMIC/FORMOSAT-3 observations of equatorial $\mathrm{F}$ region irregularities in the SAA longitude sector, J. Geophys. Res.-Space, 115, A11309, https://doi.org/10.1029/2010JA015618, 2010.

Kopp, E.: On the abundance of metal ions in the lower ionosphere, J. Geophys. Res.-Space, 102, 9667-9674, 1997.

Leighton, H. I., Shapley, A. H., and Smith, E. K.: The occurrence of sporadic $E$ during IGY, in: Ionospheric Sporadic $E$, Int. Ser. Monogr. Electromagn. Waves, vol. 2, pp. 166-177, Pergamon, Oxford, UK, 1962.

Liu, H.-L., McInerney, J. M., Santos, S., Lauritzen, P. H., Taylor, M. A., and Pedatella, N. M.: Gravity waves simulated by highresolution whole atmosphere community climate model, Geophys. Res. Lett., 41, 9106-9112, 2014.

MacDougall, J. W. and Jayachandran, P. T.: Sporadic $E$ at cusp latitudes, J. Atmos. Sol.-Terr. Phy., 67, 1419-1426, 2005.

MacDougall, J. W., Hall, G. E., and Hayashi, K.: F region gravity waves in the central polar cap, J. Geophys. Res.-Space, 102, 14513-14530, 1997.

MacDougall, J. W., Jayachandran, P. T., and Plane, J. M. C.: Polar cap Sporadic-E: part 1, observations, J. Atmos. Sol.-Terr. Phy., 62, 1155-1167, 2000a.

MacDougall, J. W., Plane, J. M. C., and Jayachandran, P. T.: Polar cap Sporadic-E: part 2, modeling, J. Atmos. Sol.-Terr. Phy., 62, 1169-1176, 2000b.

Macleod, M. A.: Sporadic $E$ theory. I. Collision-geomagnetic equilibrium, J. Atmos. Sci., 23, 96-109, 1966.

Marsh, D. R., Mills, M. J., Kinnison, D. E., Lamarque, J.-F., Calvo, N., and Polvani, L. M.: Climate change from 1850 to 2005 simulated in CESM1 (WACCM), J. Climate, 26, 7372-7391, 2013.

Mathews, J. D.: Sporadic E: current views and recent progress, J. Atmos. Sol.-Terr. Phy., 60, 413-435, 1998.

Nygren, T., Jalonen, L., Oksman, J., and Turunen, T.: The role of electric field and neutral wind direction in the formation of sporadic E-layers, J. Atmos. Terr. Phys., 46, 373-381, 1984.

Pavelyev, A. G., Liou, Y. A., Wickert, J., Schmidt, T., Pavelyev, A. A., and Liu, S.-F.: Effects of the ionosphere and solar activity on radio occultation signals: Application to CHAllenging Minisatellite Payload satellite observations, J. Geophys. Res.-Space, 112, A06326, https://doi.org/10.1029/ 2006JA011625, 2007.

Picone, J. M., Hedin, A. E., Drob, D. P., and Aikin, A. C.: NRLMSISE-00 empirical model of the atmosphere: Statistical comparisons and scientific issues, J. Geophys. Res.-Space, 107, 1468, https://doi.org/10.1029/2002JA009430, 2002.

Plane, J. M. C.: A time-resolved model of the mesospheric Na layer: constraints on the meteor input function, Atmos. Chem. Phys., 4, 627-638, https://doi.org/10.5194/acp-4-627-2004, 2004.

Plane, J. M. C.: Cosmic dust in the Earth's atmosphere, Chem. Soc. Rev., 41, 6507-6518, 2012.

Plane, J. M. C., Feng, W., and Dawkins, E. C. M. D.: The mesosphere and metals: Chemistry and changes, Chem. Rev., 115, 4497-4541, 2015.

Rocken, C., Ying-Hwa, K., Schreiner, W. S., Hunt, D., Sokolovskiy, S., and McCormick, C.: COSMIC system description, Terr. Atmos. Ocean. Sci., 11, 21-52, 2000. 
Schreiner, W., Rocken, C., Sokolovskiy, S., Syndergaard, S., and Hunt, D.: Estimates of the precision of GPS radio occultations from the COSMIC/FORMOSAT-3 mission, Geophys. Res. Lett., 34, L04808, https://doi.org/10.1029/2006GL027557, 2007.

Shinagawa, H., Miyoshi, Y., Jin, H., and Fujiwara, H.: Global distribution of neutral wind shear associated with sporadic $E$ layers derived from GAIA, J. Geophys. Res.-Space, 122, 4450-4465, 2017.

Smith, E. K.: Temperate zone sporadic- $E$ maps (fOEs $>7 \mathrm{MHz}$ ), Radio Sci., 13, 571-575, 1978.

Syndergaard, S., Schreiner, W. S., Rocken, C., Hunt, D. C., and Dymond, K. F.: Preparing for COSMIC: Inversion and analysis of ionospheric data products, in: Atmosphere and Climate, edited by: Foelsche, U., Kirchengast, G., and Steiner, A. K., 137-146, Springer, Berlin, 2006.

Thébault, E., Finlay, C. C., Beggan, C. D., et al.: International geomagnetic reference field: the 12th generation, Earth Planets Space, 67, 79, https://doi.org/10.1186/s40623-015-0228-9, 2015.

Tsunoda, R. T.: On blanketing sporadic $E$ and polarization effects near the equatorial electrojet, J. Geophys. Res.-Space, 113, A09304, https://doi.org/10.1029/2008JA013158, 2008.

Whitehead, J. D.: The formation of the sporadic- $E$ layer in the temperate zones, J. Atmos. Terr. Phys., 20, 49-58, 1961.

Whitehead, J. D.: Production and prediction of sporadic E, Rev. Geophys., 8, 65-144, 1970.

Whitehead, J. D.: Recent work on mid-latitude and equatorial sporadic-E, J. Atmos. Terr. Phys., 51, 401-424, 1989.

Williams, I. P. and Murad, E.: Meteors in the Earth's Atmosphere, Cambridge University Press, Cambridge, 2002.

Wu, D. L.: Small-scale fluctuations and scintillations in highresolution GPS/CHAMP SNR and phase data, J. Atmos. Sol.Terr. Phy., 68, 999-1017, 2006.
Wu, D. L., Ao, C. O., Hajj, G. A., de La Torre Juarez, M., and Mannucci, A. J.: Sporadic $E$ morphology from GPS-CHAMP radio occultation, J. Geophys. Res.-Space, 110, A01306, https://doi.org/10.1029/2004JA010701, 2005.

Yu, B., Xue, X., Lu, G., Ma, M., Dou, X., Qie, X., Ning, B., Hu, L., $\mathrm{Wu}, \mathrm{J}$. , and Chi, Y.: Evidence for lightning-associated enhancement of the ionospheric sporadic $E$ layer dependent on lightning stroke energy, J. Geophys. Res.-Space, 120, 9202-9212, 2015.

Yue, J., Wang, W., Richmond, A. D., and Liu, H.-L.: Quasitwo-day wave coupling of the mesosphere and lower thermosphere-ionosphere in the TIME-GCM: Two-day oscillations in the ionosphere, J. Geophys. Res.-Space, 117, A07305, https://doi.org/10.1029/2012JA017815, 2012.

Yue, X., Schreiner, W. S., Lei, J., Rocken, C., Hunt, D. C., Kuo, Y.-H., and Wan, W.: Global ionospheric response observed by COSMIC satellites during the January 2009 stratospheric sudden warming event, J. Geophys. Res.-Space, 115, A00G09, https://doi.org/10.1029/2010JA015466, 2010.

Yue, X., Schreiner, W. S., Hunt, D. C., Rocken, C., and Kuo, Y.-H.: Quantitative evaluation of the low Earth orbit satellite based slant total electron content determination, Adv. Space Res., 9, S09001, https://doi.org/10.1029/2011SW000687, 2011.

Yue, X., Schreiner, W. S., Zeng, Z., Kuo, Y.-H., and Xue, $X$ : Case study on complex sporadic $E$ layers observed by GPS radio occultations, Atmos. Meas. Tech., 8, 225-236, https://doi.org/10.5194/amt-8-225-2015, 2015.

Zeng, Z. and Sokolovskiy, S.: Effect of sporadic $E$ clouds on GPS radio occultation signals, Geophys. Res. Lett., 37, L18817, https://doi.org/10.1029/2010GL044561, 2010. 